Vol 2 Nomor 2 - Desember 2016

ISSN 2460-7878, e-ISSN 2477-5975

\title{
Evaluasi Tingkat Kualitas Hidup dengan Kriteria Eco-Settlement pada Permukiman Nelayan di Desa Pesisir Tambak Wedi
}

\author{
Qurrotul A'yun' \\ ${ }^{1}$ Universitas Islam Negeri Sunan Ampel, Surabaya, Indonesia \\ qurrotul_ayun@uinsby.ac.id
}

\begin{abstract}
As an archipelago, Indonesia has vast expanse of coastal area, that become a prominent source of economic revenue for some communities in Indonesia. Numerous fishing village was formed as a result of economic activity. But unfortunately, the condition of settlements are very dense without orientation to the sustainable environment. The low quality of human resources affect the interpretation of the definition about healthy and livable housing for the community. Research on the quality of life (liveability) of the fishermen settlement area at Tambak Wedi RT.03 RW.02 coastal village in eco-settlement concepts is necessary to investigate the possibility of restructuring the fishing village's settlement into a more livable standards and appropriately the character of the local community. This research using descriptive, evaluative and development methods. The evaluation result about liveability level at Tambak Wedi RT.03 RW.02 coastal village by the ecosettlement criteria, which is consist of ecological, social, economic and institution aspect, show that the settlement is weak in the ecological aspect. Therefore, it is the most possible aspect to be restructured with some actual and simple action, so that the fishermen settlements become liveable and has good quality of life.
\end{abstract}

Keywords: liveability, fishermen settlements, coastal area, eco-settlements

\begin{abstract}
Abstrak: Sebagai Negara kepulauan, Indonesia memiliki ribuan pulau dan sejumlah garis pantai yang menjadi andalan sumber pendapatan bagi sekelompok masyarakat. Permukiman desa-desa nelayan pun terbentuk sebagai dampak dari adanya aktivitas ekonomi tersebut. Akan tetapi nyatanya, kondisi permukiman yang muncul amatlah padat dan tidak berorientasi pada konsep lingkungan berkelanjutan. Rendahnya kualitas sumberdaya manusia ditengarai mempengaruhi pemahaman dan interpretasi masyarakat setempat mengenai pemahaman akan definisi permukiman yang sehat dan layak huni. Penelitian mengenai tingkat kualitas hidup (liveability) dengan kriteria eco-settlement pada permukiman nelayan di desa pesisir Tambak Wedi RT.03 RW.02 ini penting untuk dilakukanm terutama untuk mengidentifikasi kemungkinan restrukturisasi agar permukiman tersebut menjadi area yang layak huni dan sesuai dengan kebutuhan masyarakat setempat. Penelitian ini menggunakan metode desktiptif, evaluatif, dan development. Hasil evaluasi dan pengukuran tingkat kualitas hidup (liveability) permukiman nelayan di desa pesisir Tambak Wedi RT.03 RW.02 melalui kriteria eco-settlement, yang terdiri dari aspek ekologi, sosial, ekonomi dan kelembagaan ini menunjukkan kecenderungan permukiman tersebut masih rendah pada penilaian aspek ekologi. Oleh karena itu, aspek tersebutlah yang paling mungkin untuk direstrukturisasi dengan sejumlah aksi nyata yang sederhana, agar permukiman desa nelayan tersebut menjadi layak huni dan memiliki kualitas hidup yang baik.
\end{abstract}

Kata Kunci: tingkat kualitas hidup, permukiman nelayan, pesisir, eco-settlement 
Hidup dengan Kriteria Eco-Settlement bagi Permukiman Nelayan di Desa Pesisir Tambak Wedi

\section{PENDAHULUAN}

Indonesia merupakan Negara Kepulauan dengan jumlah pulau yang mencapai 17.508 dan panjang garis pantai kurang lebih $81.000 \mathrm{Km}$ (Dahuri, 1998). Keadaan ini, menurut Nurmalasari (2001), menyebabkan kawasan pesisir menjadi andalan sumber pendapatan bagi masyarakat. Sejalan dengan peningkatan nilai ekonomi pada daerah pesisir dan pemanfaatan sumber daya laut secara terus menerus, maka muncullah sejumlah permukiman penduduk di sekitar kawasan tersebut.

Penduduk yang bermukim di sekitar kawasan pesisir rata-rata memiliki tingkat pendidikan yang rendah. Konsekuensi dari rendahnya kualitas sumberdaya manusia ini, menurut Panjaitan dalam Suryani (2011) menyebabkan: (a) sumberdaya alam wilayah pesisir belum dapat dimanfaatkan secara optimal; (b) pola pemanfaatan sumberdaya alam tidak memperhatikan aspek-aspek kelestarian lingkungan; (c) penguasaan teknologi pemanfaatan sumberdaya pesisir masih rendah, (d) partisipasi aktif masyarakat dalam pengelolaan wilayah pesisir masih rendah; (e) sanitasi lingkungan pemukiman wilayah pesisir masih buruk.

Berdasarkan pernyataan Suryani (2011) tersebut, serta merujuk pada kondisi nyata di lapangan yang ada, maka akan sangat penting untuk melakukan evaluasi dan upaya pengembangan kualitas hidup bagi daerah permukiman nelayan ini. Terutama terkait dengan pernyataan Suryani (2011) pada poin (a) dan (b), maka amat perlu untuk mengintegrasikan usaha pemanfaatan sumber daya berkelanjutan tersebut dengan konsep eco-settlement, agar perbaikan terhadap evaluasi dari kondisi yang ada dapat berjalan secara menyeluruh. Kawasan permukiman nelayan di desa pesisir Tambak Wedi RT.03 RW.02 dipilih karena desa ini memiliki kekhasan bentuk fisik, sosial-budaya serta ekonomi masyarakat, terkait dengan lokasinya yang ada di sisi kaki jembatan Suramadu. Area penelitian dibatasi hanya pada area pesisir pantai.

\section{METODE PENELITIAN}

Penelitian ini menggunakan 3 (tiga) metode yang dikerjakan secara bertahap, yang terdiri atas metode deskriptif, evaluatif dan development. Metode Deskriptif digunakan untuk mendeskripsikan secara sistematis mengenai fakta dan karakteristik obyek yang diteliti. (Best dalam Sudikno, 2011) Pada tahapan ini penelitian dilakukan dengan mengumpulkan data dari observasi lapangan, wawancara, perekaman data (foto), serta data pendukung lain yang relevan terhadap penelitian. Sedangkan metode evaluatif menjadi metode yang berfungsi untuk memberikan penilaian bagi obyek penelitian dengan parameter tertentu (Sudikno, 2011). Metode evaluatif ini digunakan untuk mengevaluasi kondisi permukiman desa nelayan Tambak Wedi, melalui konsep ecosettlement, serta sinergi antara aspek ekologi, sosial, ekonomi dan institusi dalam menciptakan sistem permukiman yang layak huni sesuai interpretasi dan kemampuan masyarakat. Parameter penilaian yang digunakan pada proses evaluasi ini adalah sejumlah teori terkait dari para peneliti sebelumnya, dengan indikator keberhasilan berupa keberadaan serta kesesuaian kondisi obyek penelitian terhadap sejumlah parameter yang diungkapkan dalam teori terpilih tersebut.

Metode ketiga adalah metode development, yang bertujuan untuk mengembangkan pengetahuan yang sudah ada (Sudikno, 2011). Tujuan penggunaan metode ini ialah untuk mencari tahu kemungkinan restrukturisasi bagi permukiman desa nelayan menuju kriteria konsep eco-settlement, yang menjadi kriteria ideal perumahan yang layak huni, dengan didasarkan pada evaluasi yang telah dilakukan sebelumnya.

\section{HASIL DAN PEMBAHASAN}

Kawasan nelayan merupakan kawasan permukiman khusus yang menunjang kegiatan fungsi kelautan dan perikanan. Permukiman nelayan ini dilengkapi dengan fasilitas penunjang kawasan yang menyokong kehidupan ekonomi, sosial dan budaya dari penghidupan nelayan. (Peraturan Menteri Negara Perumahan Rakyat RI Nomor 15/PERMEN/M/2006 tentang Petunjuk Pelaksanaan Penyelenggaraan Pengembangan Kawasan Nelayan, 2006). Permukiman desa nelayan memiliki bentukan morfologi khusus yang mengacu pada karakteristik mata pencaharian, serta kondisi ekonomi penduduk, yang berdampak pada aktivitas publik dalam menciptakan pola permukiman. Kondisi permukiman semacam inilah yang potensial untuk dikembangkan dalam konsep eco-settlement.

\subsection{Karakteristik Fisik Permukiman Desa Nelayan Tambak Wedi RT.03 RW.02 Surabaya}

Menurut Suprijanto (2010), karakter fisik dari permukiman desa nelayan meliputi :

1. Jarak antar bangunan cenderung rapat, umumnya kumuh dan belum tertata.

2. Pola permukiman dipengaruhi oleh kondisi topografi yang dibedakan atas Pola grid atau linier, yaitu pola tata letak bangunan yang teratur di kiri dan kanan jalan, sejajar mengikuti garis pantai, serta pola cluster, tidak teratur dan organik.

3. Orientasi bangunan semula menghadap ke perairan sesuai orientasi kegiatan, tetapi kini, orientasi permukiman lebih mempertimbangkan aspek fungsional dan aksesibilitas.

4. Tipologi bangunan menggunakan struktur dan konstruksi sederhana, dan konvensional. 


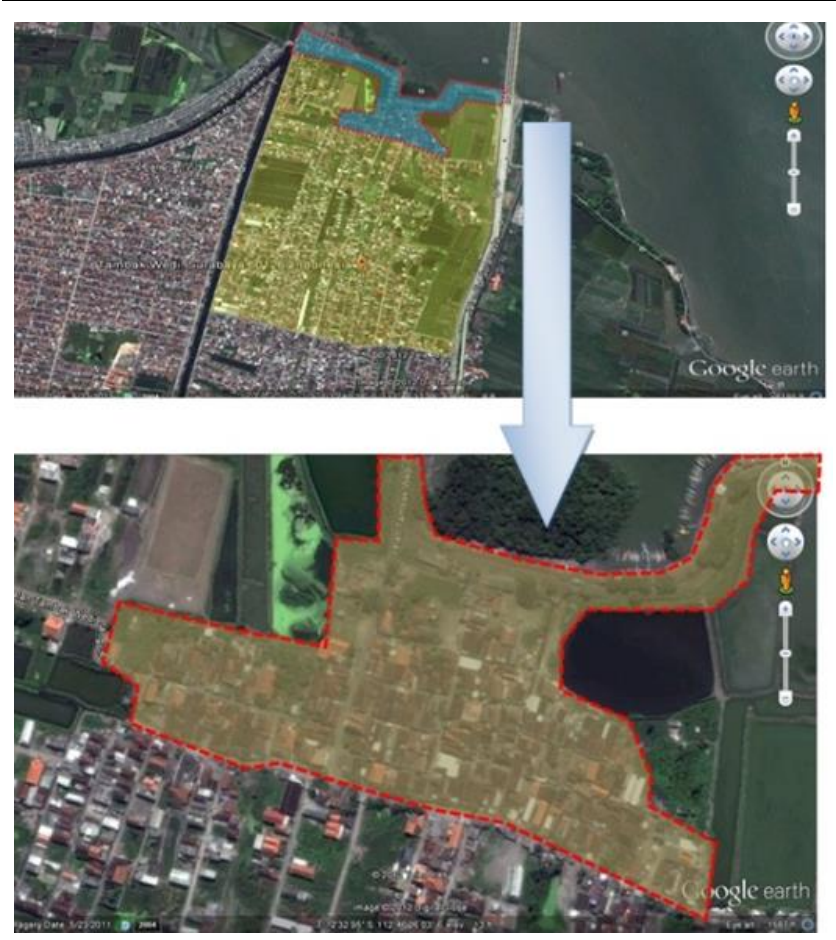

Gambar 1. Lokasi penelitian di Desa Tambak Wedi (sumber : analisis, 2014)

Desa Tambak Wedi merupakan salah satu permukiman nelayan di sisi timur laut Surabaya yang memiliki beberapa karakteristik fisik sebagai berikut:

1) Kepadatan bangunan yang tinggi dan minimnya ruang terbuka, dengan jarak antar rumah hanya sekitar \pm 1 meter, mengakibatkan minimnya pula pencahayaan dan penghawaan alami serta ketidakteraturan penataan bangunan.

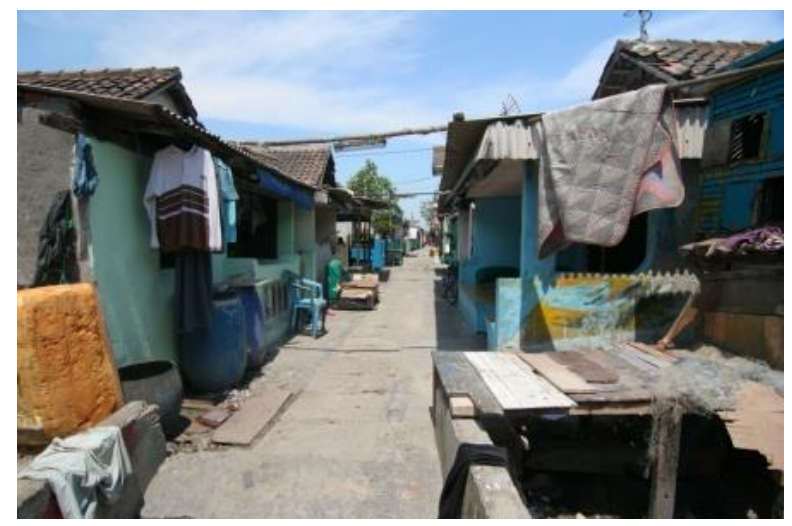

Gambar 2. Kepadatan permukiman yang tinggi di Desa Tambak Wedi, Surabaya (sumber: observasi, 2014)

2) Pola permukiman cluster-organik. Permukiman nelayan di Desa Tambak Wedi awalnya berpola linier mengikuti garis pantai, namun kini polanya cenderung cluster-organik.

3) Permukiman tidak lagi menghadap laut, namun cenderung lebih fleksibel karena mengedepankan aspek fungsional dan aksesbilitas, sesuai dengan yang diungkapkan oleh Suprijanto (2010).
4) Tipologi dan luasan bangunan yang spesifik, dimana di desa ini, bangunan yang menggunakan tipologi konstruksi tradisional hanya terlihat di sejumlah area saja. Sementara sisanya, telah dibangun secara permanen dengan menggunakan batu bata dan beton sebagai dinding. Pada tabel 1. menunjukkan gambaran kondisi tipologi dan luasan bangunan di desa pesisir Tambak Wedi

Tabel 1. Tipologi dan Luasan Bangunan

\begin{tabular}{ll}
\hline \multicolumn{1}{c}{ Aspek } & \multicolumn{1}{c}{ Kondisi } \\
\hline Tipologi \\
Bangunan & $\begin{array}{l}\text { Sekitar } 3 \% \text { rumah penduduk yang dalam } \\
\text { kondisi kurang layak huni atau memiliki } \\
\text { tingkat kerusakan }>50 \% .\end{array}$ \\
\hline
\end{tabular}

Sebagian besar rumah penduduk $(76 \%)$ merupakan jenis hunian nelayan yang layak huni dengan tingkat kerusakan antara $25-50 \%$.

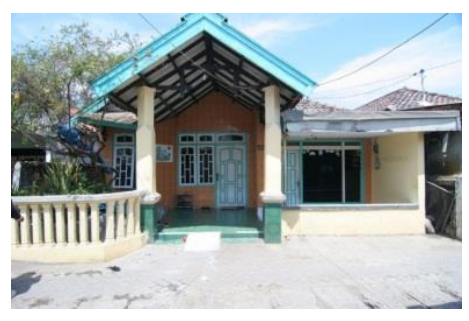

Kini mulai banyak bermunculan rumahrumah nelayan dengan gaya modern, yang kontras dengan sekitarnya, dengan prosentase sebesar $20 \%$.
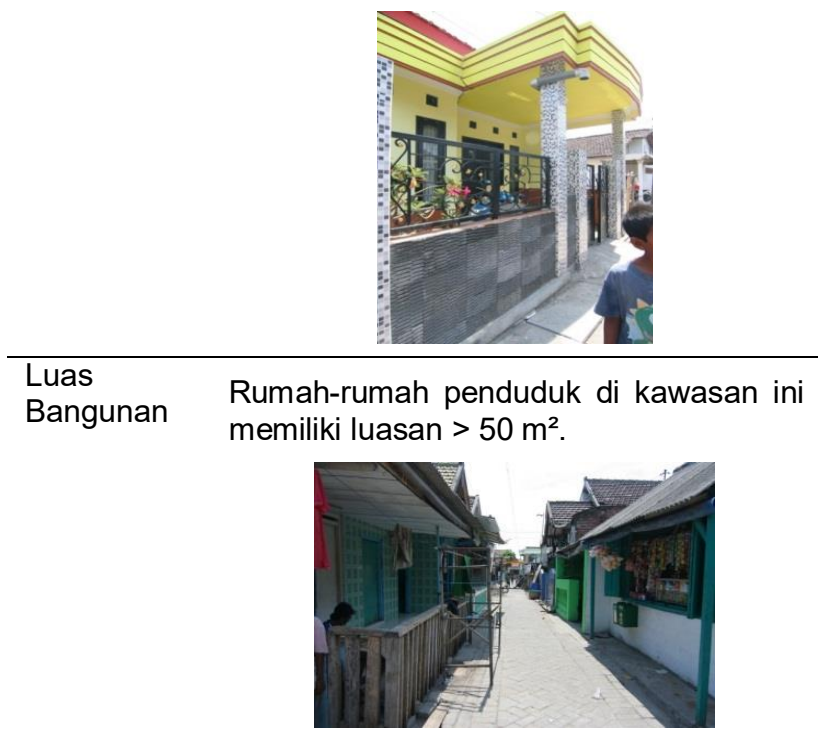

Sumber : observasi, 2014 


\subsection{Penerapan Prinsip Eco-Settlement pada Permukiman Nelayan di Desa Tambak Wedi}

Menurut Suryani (2011) konsep eco-settlement adalah suatu konsep penataan permukiman dengan mengharmonisasikan aspek sosial, ekonomi dan ekologi menuju keberlanjutan ekosistem dengan didukung oleh sistem kelembagaan yang kapabel. Jika digambarkan, maka konsep eco-settlement dapat didefinisikan dalam Gambar 3. berikut :

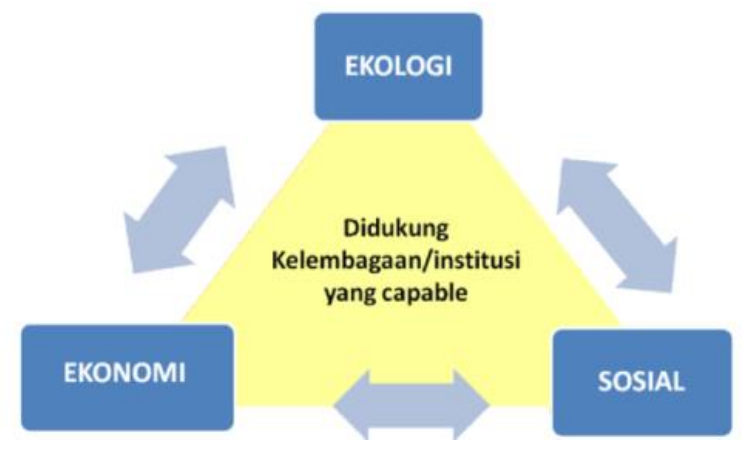

Gambar 3. Aspek-aspek yang terkait dengan ecosettlement (sumber : Suryani, 2011)

Menurut Puslitbangkim Kementerian Pekerjaan Umum (2006), kriteria eco-settlement didefinisikan dalam Tabel 2. berikut :

Tabel 2. Kriteria Eco-Settlement

\begin{tabular}{|c|c|}
\hline $\begin{array}{l}\text { Aspek } \\
\text { Eco-Settlements }\end{array}$ & Kriteria \\
\hline \multirow[t]{8}{*}{ Ekologi } & Biodiversity \\
\hline & Kualitas udara \\
\hline & Kualitas dan kuantitas air \\
\hline & Rumah sehat \\
\hline & Guna lahan \\
\hline & Perubahan iklim \\
\hline & Energi \\
\hline & $\begin{array}{l}\text { Teknologi berwawasan } \\
\text { lingkungan }\end{array}$ \\
\hline \multirow[t]{2}{*}{ Sosial } & $\begin{array}{l}\text { Kapasitas masyarakat } \\
\text { (pendidikan, partisipasi, } \\
\text { kebiasaan) }\end{array}$ \\
\hline & Pemberdayaan masyarakat \\
\hline \multirow[t]{3}{*}{ Ekonomi } & Inovasi teknologi \\
\hline & $\begin{array}{l}\text { Local economic development } \\
\text { (kesempatan kerja, peningkatan } \\
\text { kesejahteraan/pendapatan) }\end{array}$ \\
\hline & Aksesbilitas (transportasi) \\
\hline Kelembagaan & $\begin{array}{l}\text { Kapasitas institusi (kerjasama, } \\
\text { dan dukungan kebijakan) }\end{array}$ \\
\hline
\end{tabular}

Sumber : Puslitbangkim, 2006

\subsubsection{Aspek Ekologi}

\section{Biodiversity}

Keanekaragaman hayati pada kampung nelayan di Desa Tambak Wedi, tercermin dari adanya keberagaman hasil tangkapan ikan nelayan.

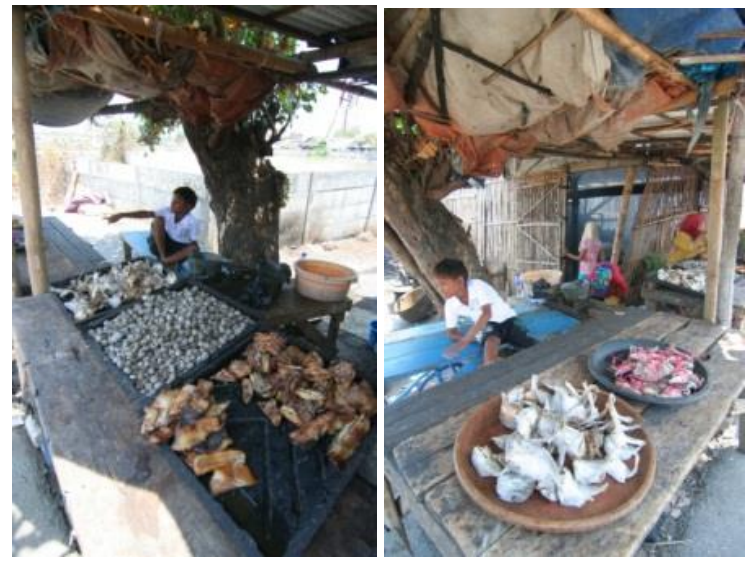

Gambar 4. Biodiversity pada Desa Nelayan Tambak Wedi (sumber : observasi, 2014)

\section{Kualitas Udara}

Kualitas udara di permukiman nelayan di Desa Tambak Wedi, cenderung buruk, karena terjadi polusi udara yang disebabkan oleh bau dari tumpukan sampah dan berbagai limbah. Produksi oksigen juga kurang teregulasi dengan baik karena minimnya pepohonon.

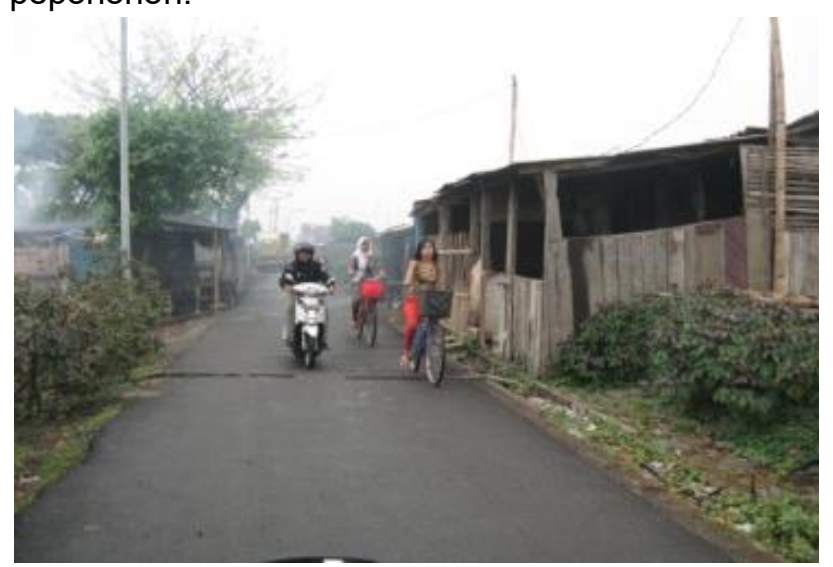

Gambar 5. Kualitas udara yang relatif buruk dan minimnya vegetasi (sumber: observasi, 2014)

\section{Kualitas dan Kuantitas Air}

a) Penggunaan Air Bersih

Secara kuantitas kebutuhan air di masyarakat cukup terpenuhi, namun dari segi kualitas cenderung masih memprihatinkan. Mayoritas penduduk, $83 \%$ telah menggunakan PDAM, tetapi $14 \%$ masih ada yang menggunakan sumber air yang dijual oleh penjaja keliling. Bahkan sebesar $3 \%$ penduduk yang berlokasi lebih dekat dengan laut, menggunakan sumber air tercemar. 


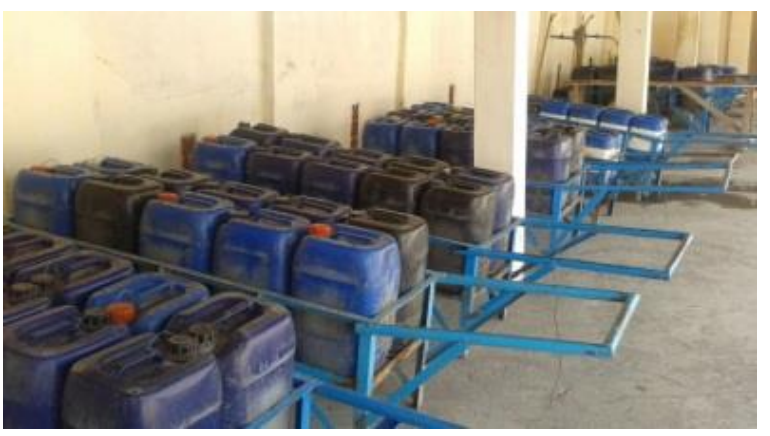

Gambar 6. Air bersih dari penjaja keliling

(sumber : dokumen pribadi, 2014)

b) Pengelolaan Sanitasi Limbah Rumah Tangga Hanya $25 \%$ penduduk yang memiliki KM/NC dengan septic tank, dan 5\% menggunakan KMNC umum. Sebesar $70 \%$ penduduk masih membuang limbah domestik mereka ke sungai, dan itupun tanpa bilik. Mereka berpendapat bahwa masih sangatlah aneh untuk menggunakan WC modern.

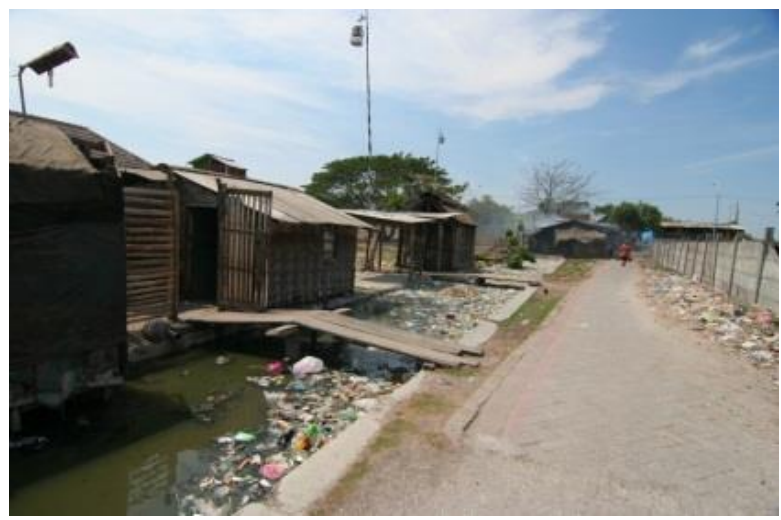

Gambar 7. Sungai yang dipakai untuk pembuangan limbah domestik penduduk

(sumber : observasi, 2014)

c) Kondisi Drainase Lingkungan (Lama Genangan Air Hujan)

Jika terjadi hujan, maka genangan yang terjadi $70 \%$ akan menyurut rata-rata dalam kurun waktu 1-2 jam. Sedangkan sisanya akan menyurut $\leq 1$ jam atau bahkan $\leq 2$ jam. Genangan air hujan ini cenderung surut lebih lama karena banyaknya sampah yang mengapung di sekitar aliran sungai.

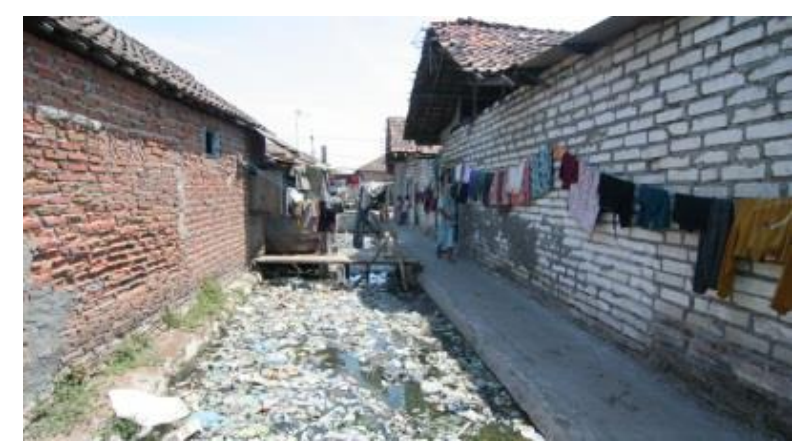

Gambar 8. Kondisi drainase

(sumber : dokumen pribadi, 2014)

\section{Rumah Sehat}

Syarat rumah sehat diantaranya ketersediaan jamban sehat, kualitas pencahayaan dan penghawaan yang baik, tidak adanya serangga dalam rumah, kesesuain kapasitas jiwa di dalam rumah berdasarkan jumlah kepala keluarga, tersedianya pembuangan air limbah yang memadai, kondisi tempat sampah dan tidak adanya jentik-jentik nyamuk di penampungan air atau bak di setiap rumah. (Depkes RI, 2003). Dari semua parameter rumah sehat di atas, berdasarkan hasil amatan, $79 \%$ rumah penduduk $(79 \%)$ di permukiman nelayan Desa Tambak Wedi tidak memiliki satupun parameter yang dimaksud. Secara lebih terperinci, hal ini terlihat dalam Tabel 3.

Tabel 3. Kondisi permukiman Desa Tambak Wedi dikaitkan dengan kriteria rumah sehat

\begin{tabular}{|c|c|c|}
\hline $\begin{array}{l}\mathbf{N} \\
\mathbf{0}\end{array}$ & $\begin{array}{c}\text { Parameter } \\
\text { Rumah Sehat }\end{array}$ & $\begin{array}{l}\text { Kondisi Desa Nelayan } \\
\text { Tambak Wedi }\end{array}$ \\
\hline 1 & Jamban sehat & $\begin{array}{l}\text { Masyarakat seringkali buang air } \\
\text { besar di sepanjang sungai di } \\
\text { sekitar rumah. }\end{array}$ \\
\hline 2 & $\begin{array}{l}\text { Kondisi } \\
\text { Pencahayaan } \\
\text { Alami }\end{array}$ & $\begin{array}{l}\text { Kualitas pencahayaan alaminya } \\
\text { tidak begitu bagus, sebab } \\
\text { koridor jalan di antara rumah } \\
\text { dipenuhi dengan sejumlah } \\
\text { barang. }\end{array}$ \\
\hline 3 & $\begin{array}{l}\text { Penghawaan } \\
\text { alami }\end{array}$ & $\begin{array}{l}\text { Minimnya jendela ventilasi dan } \\
\text { sedikitnya ruang antar } \\
\text { bangunan, membuat kualitas } \\
\text { udara dalam rumah, cenderung } \\
\text { buruk. }\end{array}$ \\
\hline 4 & $\begin{array}{l}\text { Kehadiran } \\
\text { serangga }\end{array}$ & $\begin{array}{l}\text { Kualitas higienitas rumah yang } \\
\text { tidak dijaga, membuat banyak } \\
\text { serangga bermunculan. }\end{array}$ \\
\hline 5 & $\begin{array}{l}\text { Kepadatan } \\
\text { hunian }\end{array}$ & $\begin{array}{l}\text { Banyak rumah yang kapasitas } \\
\text { penggunanya melebihi standar } \\
\text { jiwa } / \mathrm{m}^{2} \text {. }\end{array}$ \\
\hline 6 & $\begin{array}{l}\text { Pembuangan } \\
\text { Limbah }\end{array}$ & $\begin{array}{l}\text { Tidak ada tempat pembuangan } \\
\text { air limbah yang terorganisir, } \\
\text { sehingga air limbah tersebut } \\
\text { langsung dibuang ke sungai } \\
\text { dan justru membuat } \\
\text { pencemaran lingkungan. }\end{array}$ \\
\hline 7 & $\begin{array}{l}\text { Fasilitas } \\
\text { pengelolaan } \\
\text { sampah }\end{array}$ & $\begin{array}{l}\text { Pemerintah memiliki wacana } \\
\text { untuk memberikan bantuan } \\
\text { dalam pengelolaan sampah. } \\
\text { Namun untuk saat ini } \\
\text { progresnya masih mencapai 3\% } \\
\text { karena masih dalam tahap } \\
\text { rencana yang baru disetujui. } \\
\text { Desa ini sebenarnya sudah } \\
\text { memiliki tempat pembuangan } \\
\text { sampah meski belum dikelola } \\
\text { secara maksimal. Namun yang } \\
\text { paling mengkhawatirkan ialah } \\
\text { hampir } 70 \% \text { sampah dan limbah } \\
\text { langsung dibuang ke sungai. }\end{array}$ \\
\hline 8 & $\begin{array}{l}\text { Keberaadaan } \\
\text { jentik nyamuk }\end{array}$ & $\begin{array}{l}\text { Kurangnya perhatian terhadap } \\
\text { kebersihan lingkungan, tentu } \\
\text { saja membawa larva-larva } \\
\text { nyamuk dalam air. }\end{array}$ \\
\hline
\end{tabular}

Sumber : analisis, 2014 


\section{Guna Lahan}

Lahan di permukiman nelayan Desa Tambak Wedi, kebanyakan didominasi oleh rumah-rumah penduduk, dan beberapa bagian digunakan untuk tempat-tempat penjualan ikan berupa gubuk, yang diletakkan di dekat bibir pantai. Ruang terbuka untuk tempat anak-anak bermain pun, masih belum terwadahi dengan baik.

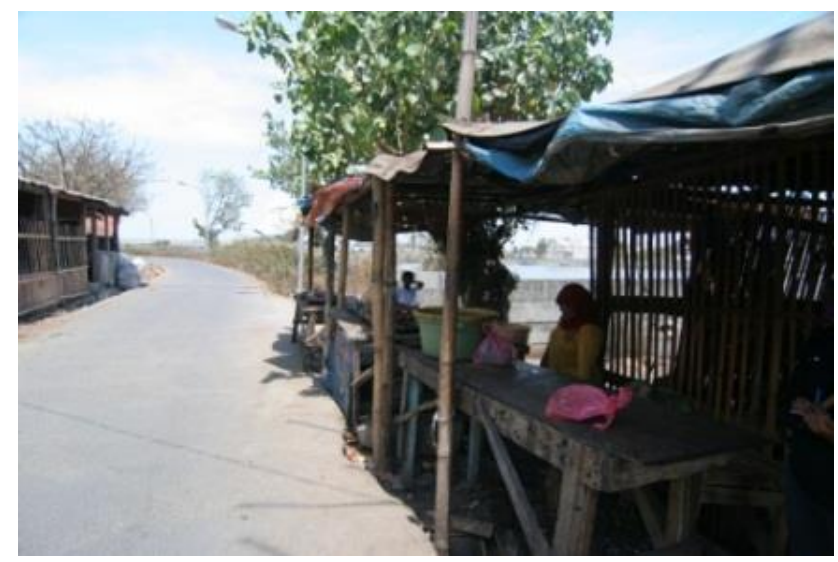

Gambar 9. Gubuk tempat penjualan ikan di area pinggir pantai (sumber : observasi, 2014)

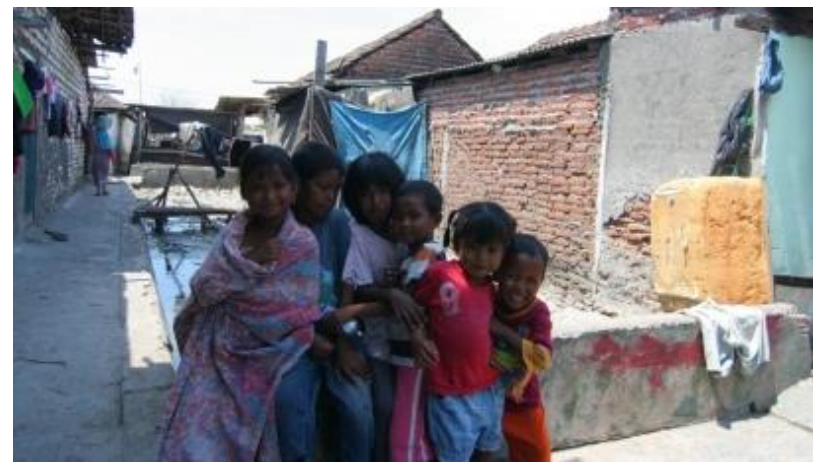

Gambar 10. Tempat bermain anak-anak di pinggiran sungai (sumber : observasi, 2014)

\section{Perubahan Iklim}

Perubahan iklim berpengaruh pada aktivitas para penduduk yang berprofesi sebagai nelayan dalam menangkap ikan. Jika tiba musim cekikan (AgustusOktober), nelayan akan kesulitan untuk mencari ikan karena air laut yang terus surut. Sehingga mata pencaharian penduduk dan pola aktivitasnya pun cenderung beralih ke tambak.

\section{Energi}

Belum ada upaya untuk menyediakan energi terbarukan, meski di sekitar permukiman terdapat sumber energi alternatif yang besar yaitu air. Kebutuhan energi listrik, masih sepenuhnya tergantung dari pasokan PLN.

\section{Teknologi Berwawasan Lingkungan}

Teknologi berwawasan lingkungan belum diketahui secara luas oleh penduduk. Akan tetapi teknologi sederhana berwawasan lingkungan yang telah digunakan oleh penduduk ialah metode dalam penangkapan ikan yang masih menggunakan metode tradisional dengan menggunakan jaring jala. Sehingga hal tersebut tidak akan merusak lingkungan.

\subsubsection{Aspek Sosial Kapasitas Masyarakat}

Kurangnya pengetahuan dan pendidikan warga, diakui oleh Bapak Mustofa, ketua kelompok nelayan di Desa Tambak Wedi. Hal tersebut kemudian menjadi salah satu kendala dalam optimalisasi kapasitas masyarakat.

\section{Pemberdayaan Masyarakat}

a) Keterlibatan Masyarakat dalam Kegiatan Sosial Seluruh warga berperan aktif dalam keterlibatannya pada kegiatan sosial di lingkungan Rukun Tetangga (RT)

b) Pengelolaan Kelompok Usaha Kecil

Dalam pengelolaan usaha kecil pun, semua warga turut aktif dan terlibat di setiap posko yang ada.

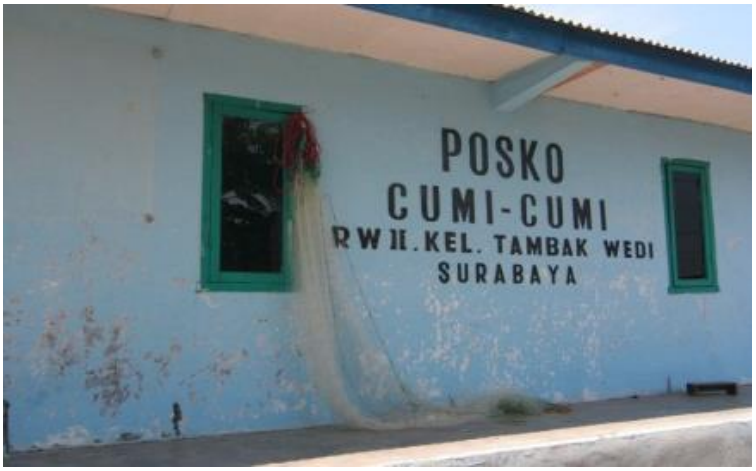

Gambar 11. Keterlibatan masyarakat dalam pengelolaan usaha kecil (sumber: observasi, 2014)

c) Partisipasi Masyarakat dalam Pengelolaan Lingkungan Permukiman

Angka partisipasi masyarakat dalam pengelolaan lingkungan permukiman yang dilakukan setiap hari minggu hanya mencapai $56 \%$. Sisanya dilakukan secara insidentil jika ada acara selamatan kelautan saja.

\subsubsection{Aspek Ekonomi Inovasi Teknologi}

Hasil pengamatan terhadap peralatan yang digunakan dalam aktivitas warga, tidak ditemukan adanya ada inovasi teknologi. Inovasi lebih banyak dilakukan dalam bidang pengolahan hasil perikanan. Sekitar $85 \%$ hasil perikanan berupa rajungan dan memiliki pengolahan dalam skala besar di salah satu pabrik di area desa Tambak Wedi hingga ke proses pengalengan. Akan tetapi, sayangnya produk ini dijual dengan harga yang murah karena proses pelabelan hingga eksport di lakukan oleh perusahaan. 


\section{Local Economy Development}

Terbentuknya permukiman desa nelayan ini secara tidak langsung menciptakan stabilitas perekonomian mikro tersendiri pada skala Desa Tambak Wedi karena mampu menciptakan lapangan bagi sebagian besar warga di sana serta dapat meningkatkan kesejahteraan warga setempat. Para pria bekerja sebagai nelayan sedangkan wanita berperan sebagai pengolah hasil tangkapan ikannya.

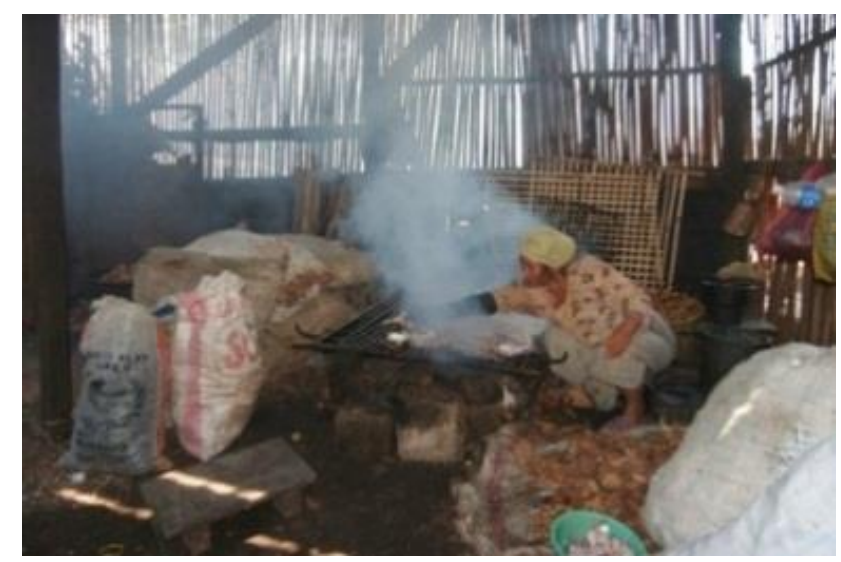

Gambar 12. Kegiatan pengolahan hasil tangkapan ikan (sumber : observasi, 2014)

\section{Aksesbilitas (Transportasi)}

Sebesar $92 \%$ jalan di desa Tambak Wedi kondisinya berupa paving/cor/aspal serta dalam kondisi terawat dengan baik, sedangkan Sisanya, sejumlah $8 \%$ kondisi jalan berupa perkerasan yang kurang terawat dengan baik.

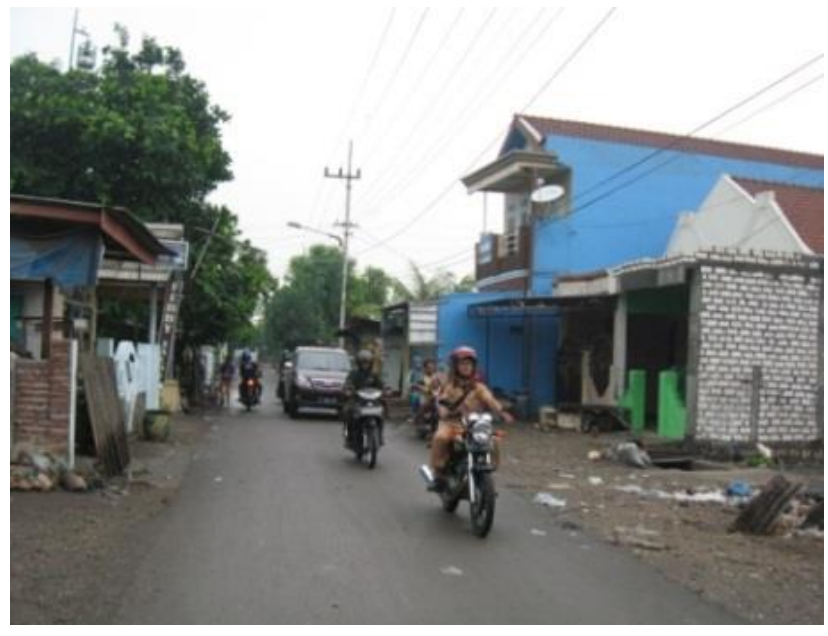

Gambar 13. Jalan di Desa Tambak Wedi yang kondisinya terawat dengan baik (sumber: observasi, 2014)

Kondisi jalan yang baik tentu akan memberikan kenyamanan bagi pengguna moda transportasi yang melewatinya. Akan tetapi, sayangnya tidak ada transportasi publik yang melewati area tersebut.

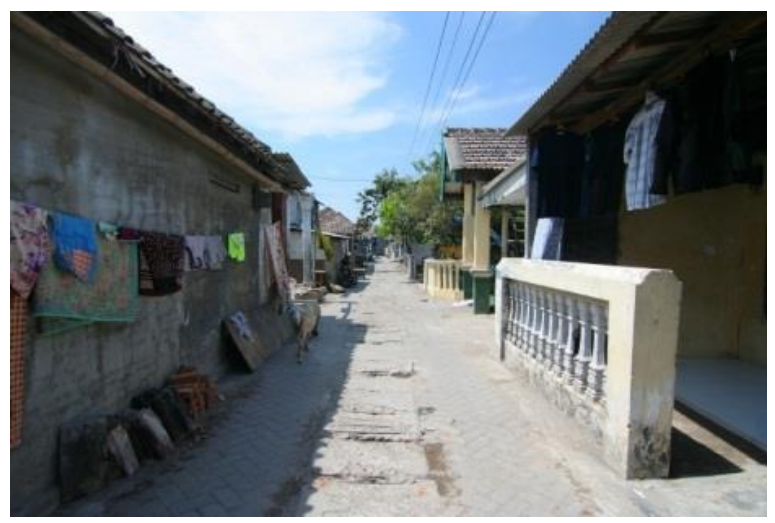

Gambar 14. Kondisi jalan di Desa Tambak Wedi yang kurang terawat dengan baik (sumber: observasi, 2014)

\subsubsection{Aspek Kelembagaan}

Peranan institusi dalam keberlangsungan kerjasama dan dukungan kebijakan di bidang perikanan sudah cukup terjalin secara intens dengan pemerintah kota setempat, dalam bentuk penyuluhan-penyuluhan maupun pendanaan yang disediakan untuk kampung tersebut. Koperasi pun menjadi salah satu fasilitas ekonomi yang tersedia bagi masyarakat Desa Tambak Wedi, dengan kondisi yang baik dan terletak di area yang terjangkau. Meski demikian, masih ada sekitar 4\% fasilitas ekonomi berupa tempat produksi, pengolahan dan penjualan ikan yang jarak jangkauannya cukup jauh dari permukiman penduduk.

\subsection{Evaluasi Penilaian Tingkat Kualitas Hidup dari dengan Parameter Eco-Settlement}

Liveability di dalam konteks permukiman merupakan gambaran progres pencapaian kualitas hidup dari suatu kawasan hunian, melalui sejumlah faktor, yang tercermin dalam kondisi fisik dan karakteristik ruang di wilayah tersebut. Untuk mengukur pencapaian kualitas hidup (liveability) di permukiman nelayan di permukiman nelayan di Desa Tambak Wedi RT.03 RW.02 ini, dilakukan dengan menggunakan parameter yang ada pada kriteria eco-settlemen dari Puslitbangkim (2006). Sedangkan evaluasi penilaian terhadap indikator keberhasilannya, dilakukan dengan memberi scoring terhadap sesuai atau tidaknya deskripsi kondisi obyek penelitian terhadap sejumlah parameter yang telah ditentukan.

Evaluasi penilaian tingkat kualitas hidup (liveability) pada tabel 4 berikut, merupakan kesimpulan global mengenai penerapan konsep ecosettlement pada permukiman nelayan Desa Tambak Wedi RT.03 RW.02. 
Tabel 4. Penilaian tingkat kualitas hidup di Desa Tambak Wedi dengan parameter eco-settlement

\begin{tabular}{|c|c|c|c|c|c|c|c|}
\hline $\begin{array}{l}\mathbf{N} \\
\mathbf{O}\end{array}$ & Kriteria & $\begin{array}{l}T \\
S\end{array}$ & KS & $\mathbf{s}$ & sS & $\begin{array}{l}\text { Total } \\
\text { Nilai }\end{array}$ & $\begin{array}{c}\% \\
\text { Capai } \\
\text { an }\end{array}$ \\
\hline \multirow[t]{10}{*}{1} & EKOLOGI & & & & & & \\
\hline & Biodiversity & & & & $\sqrt{ }$ & & \\
\hline & Kualitas udara & $\sqrt{ }$ & & & & & \\
\hline & $\begin{array}{l}\text { Kualitas dan } \\
\text { kuantitas air }\end{array}$ & $\sqrt{ }$ & & & & & \\
\hline & Rumah sehat & $\sqrt{ }$ & & & & & \\
\hline & Guna lahan & & $\sqrt{ }$ & & & & \\
\hline & Perubahan iklim & & & $\sqrt{ }$ & & & \\
\hline & Energi & & $\sqrt{ }$ & & & & \\
\hline & $\begin{array}{r}\text { Teknologi } \\
\text { berwawasan } \\
\text { lingkungan }\end{array}$ & & & $\sqrt{ }$ & & & \\
\hline & & & & & & 17 & 53,1 \\
\hline \multirow[t]{4}{*}{2} & SOSIAL & & & & & & \\
\hline & $\begin{array}{r}\text { Kapasitas } \\
\text { masyarakat }\end{array}$ & & $\sqrt{ }$ & & & & \\
\hline & $\begin{array}{r}\text { Pemberdayaan } \\
\text { masyarakat }\end{array}$ & & & & $\sqrt{ }$ & & \\
\hline & & & & & & 6 & 75,0 \\
\hline \multirow[t]{5}{*}{3} & EKONOMI & & & & & & \\
\hline & Inovasi teknologi & & & $\sqrt{ }$ & & & \\
\hline & $\begin{array}{r}\text { Local economic } \\
\text { development }\end{array}$ & & & & $\sqrt{ }$ & & \\
\hline & Aksesbilitas & & & $\sqrt{ }$ & & & \\
\hline & & & & & & 10 & 83,3 \\
\hline \multirow[t]{3}{*}{4} & KELEMBAGAAN & & & & & & \\
\hline & $\begin{array}{l}\text { Kapasitas } \\
\text { institusi }\end{array}$ & & & $\sqrt{ }$ & & & \\
\hline & & & & & & 3 & 75,0 \\
\hline
\end{tabular}

Sumber : analisis, 2016

Keterangan :

TS : Tidak Sesuai dengan kriteria eco-settlement (score 1)

KS : Kurang Sesuai dengan kriteria eco-settlement (score 2)

$S \quad$ : Sesuai dengan kriteria eco-settlement (score 3)

SS : Sangat Sesuai dengan kriteria eco-settlement (score 4)

\subsection{Upaya Peningkatan Kualitas Hidup dengan Parameter Eco-Settlement Permukiman Nelayan di Desa Tambak Wedi}

Dari hasil evaluasi pada tabel 4. terlihat bahwa di dalam aspek ekologi, jabaran kriteria yang bernilai paling rendah di dalam parameter eco-settlement ialah dalam hal : (a) kualitas udara; (b) kualitas dan kuantitas air; dan (c) kriteria rumah sehat. Ketiga masalah tersebut, berdasarkah hasil amatan berakar pada persoalan manajemen limbah yang masih lemah. Oleh karenanya beberapa langkah yang dapat dilakukan terkait restrukturisasi permukiman di Desa nelayan Tambak Wedi beserta excpected outcome nya dapat dilihat pada tabel 5 .

Tabel 5. Aksi nyata dan pengaruh dari program manajemen limbah pada restrukturisasi permukiman desa nelayan dalam konsep eco-settlement

\begin{tabular}{|c|c|c|}
\hline Aspek & Aksi & $\begin{array}{c}\text { Pengaruh yang } \\
\text { diharapkan }\end{array}$ \\
\hline 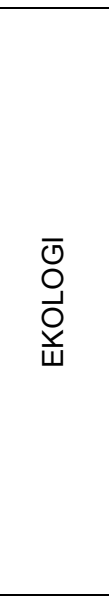 & $\begin{array}{l}\text { Mengembangkan } \\
\text { bank sampah, } \\
\text { yang dipisahkan } \\
\text { antara sampah } \\
\text { kering dan } \\
\text { sampah basah, } \\
\text { untuk diproses } \\
\text { kemudian } \\
\text { Membuat alat } \\
\text { pengolah air } \\
\text { limbah dengan } \\
\text { teknologi } \\
\text { sederhana }\end{array}$ & $\begin{array}{l}\text { - Sampah yang } \\
\text { direduksi, dapat } \\
\text { meningkatkan } \\
\text { kesehatan lingkungan. } \\
\text { - Sampah kering dapat } \\
\text { direcycle menjadi } \\
\text { kerajinan tangan, } \\
\text { sehingga mengurangi } \\
\text { polusi lingkungan } \\
\text { - Hasil pengolahan } \\
\text { sampah basah oleh } \\
\text { komposer dan biopori, } \\
\text { dapat menyuburkan } \\
\text { tanah } \\
\text { - Menstabilkan pH air } \\
\text { limbah yang sesuai } \\
\text { untuk lingkungan }\end{array}$ \\
\hline $\begin{array}{l}\frac{1}{⿺} \\
\text { क } \\
\text { क }\end{array}$ & $\begin{array}{l}\text { Partisipasi aktif } \\
\text { masyarakat dalam } \\
\text { manajemen sampah } \\
\text { dan lingkungan secara } \\
\text { terorganisasi }\end{array}$ & $\begin{array}{l}\text { Kualitas interaksi dan } \\
\text { hubungan antara } \\
\text { masyarakat di dalam } \\
\text { komunitas dapat } \\
\text { ditingkatkan }\end{array}$ \\
\hline 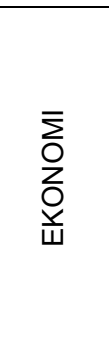 & $\begin{array}{l}\text { Mengembangkan } \\
\text { sampah sebagai } \\
\text { material yang dapat } \\
\text { direcycle dan diproses } \\
\text { ke dalam sejumlah } \\
\text { bentuk kerajinan, } \\
\text { seperti aksesoris dan } \\
\text { dekorasi rumah yang } \\
\text { dapat dijual pada } \\
\text { publik }\end{array}$ & $\begin{array}{l}\text { - Menambah sumber } \\
\text { pendapatan ekonomi } \\
\text { - Memobilisasi } \\
\text { ekonomi kecil lokal }\end{array}$ \\
\hline 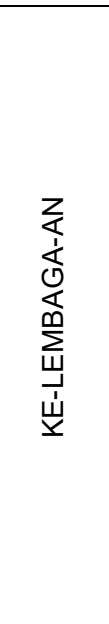 & $\begin{array}{l}\text { - Mempromosikan } \\
\text { program lingkungan } \\
\text { berbasis partisipasi } \\
\text { masyarakat } \\
\text { - Menyediakan wakil } \\
\text { untuk meningkatkan } \\
\text { partisipasi lokal } \\
\text { pada lingkungan } \\
\text { - Memfasilitasi } \\
\text { pembentukan } \\
\text { kader-kader } \\
\text { lingkungan } \\
\text { - Mengevaluasi } \\
\text { kinerja sistem } \\
\text { kelembagaan agar } \\
\text { dapat berlangsung } \\
\text { secara terus- } \\
\text { menerus }\end{array}$ & $\begin{array}{l}\text { Menjaga dan } \\
\text { meningkatkan } \\
\text { kesadaran publik untuk } \\
\text { menciptakan lingkungan } \\
\text { permukiman yang sehat }\end{array}$ \\
\hline
\end{tabular}

Sumber : analisis, 2016 


\section{KESIMPULAN}

Dari sejumlah aspek liveability (kualitas hidup) yang diteliti dengan menggunakan parameter ecosettlement yang ada pada Tabel 4, jika diurutkan berdasarkan kondisi eksisting kawasan, masyarakat di permukiman nelayan Desa Tambak Wedi, cederung memprioritaskan kawasan permukiman yang mereka huni berorientasi pada : (1) aspek ekonomi, untuk menunjang kebutuhan hidup; (2) aspek sosial, dalam kaitannya dengan hubungan kemasyarakatan seprofesi; (3) aspek kelembagaan, yang menunjang keberlangsungan kegiatan ekonominya, serta (4) aspek ekologi, yang mereka definisikan dalam bentuk memaksimalkan penggunaan sumber daya lingkungan. Bagi penduduk setempat, aspek ekologi dalam bentuk keberlanjutan dan kesehatan lingkungan kurang begitu penting karena tidak memberikan keuntungan secara finansial bagi mereka yang berpenghasilan rendah padahal memiliki efek mendalam dalam proses kelangsungan hidup di permukiman desa nelayan.

Untuk menyadarkan pentingnya kepedulian dalam meningkatkan liveability (kualitas hidup) masyarakat dari segi ekologi, hendaknya dilakukan dengan caracara yang dapat dipahami oleh masyarakat nelayan itu sendiri, dengan biaya yang murah dan terjangkau. Langkah kecil sederhana untuk merestrukturisasi permukiman dari aspek ekologi, terkait dengan rendahnya kualitas udara, air dan rumah sehat tersebut, dapat dimulai dengan menerapkan sistem pengolahan limbah 3R (Reduce, Reuse, Recycle). Harapannya, tindakan aktual ini akan mudah untuk dilaksanakan dan mempengaruhi keberlanjutan ketiga komponen eco-settlement yang lain, dalam meningkatkan liveability (kualitas hidup) masyarakat.

\section{DAFTAR PUSTAKA}

Dahuri. (1998) Kebutuhan Riset untuk Mendukung Implementasi Pengelolaan Sumberdaya Pesisir dan Lautan Secara Terpadu. Jurnal Pesisir dan Lautan, Vol. 1, No.2, hal 53-65. PKSPL-IPB. Bogor.

Depkes RI. (2013). Profil Kesehatan Indonesia Tahun 2013. Depkes RI. Jakarta.

Kementerian Negara Perumahan Rakyat RI. (2006). Petunjuk Pelaksanaan Penyelenggaraan dan Pengembangan Kawasan Nelayan Nomor 15/PERMEN/M/2006 Peraturan Menteri Negara Perumahan Rakyat Republik Indonesia.

Nurmalasari, Y. (2001). Analisa Pengelolaan Wilayah Pesisir bagi Masyarakat. Jurnal online http://www.stmik-

im.ac.id/userfiles/jurnal\%20yessy.pdf.

Puslitbang. (2006). Penerapan Eco-Settlements di Hulu DAS Cimanuk. Pusat Penelitian dan Pengembangan Permukiman. Puslitbang. Bandung. Jurnal online http://puskim.pu.go.id/wp- content/uploads/2016/10/eco-settlements.pdf

Sudikno, A. (2011). Metode Pelestarian Arsitektur. Jurnal online https://www.academia.edu/7761446/METODE_P ELESTARIAN_ARSITEKTUR.

Suryani, A. S. (2011). Tantangan Implementasi Konsep Eco-Settlement Dalam Undang-Undang No. 1 Tahun 2011 Tentang Perumahan dan Kawasan Permukiman. Jurnal Aspirasi (Trial), 2(1), 1-15.

Suprijanto, I. (2001). Karakteristik Spesifik, Permasalahan dan Potensi Pengembangan Kawasan Kota Tepi Laut / Pantai (Coastal City) di Indonesia. Proceeding - Studi Dampak Timbal Balik Antar Pembangunan Kota dan Perumahan di Indonesia dan Lingkungan Global. 